\title{
MENINGKATKAN KEMAMPUAN MENYELESAIKAN OPERASI HITUNG PERKALIAN MELALUI PENGGUNAAN MEDIA TALI PAS
}

\author{
Purwandari Suciningtyas \\ SDN Paciran I, \\ Kecamatan Paciran, Kabupaten Lamongan
}

\begin{abstract}
This study aims to describe students' activeness of the class when it is applied to the media and the improvement of learning outcomes of the students of grade V SDN Paciran I Lamongan 2016/2017 academic year in completing multiplication counting operation through the use of laces. This research belongs to classroom action research. Data obtained in the form of formative test results, observation sheet of teaching and learning activities. The learning outcomes of multiply counting operations by applying the wrist strap medium from cycle 1 to cycle 2 experience, a very satisfactory improvement. In cycle 1, there is an increase of students who fulfill KKM that is 50\%, while in cycle 2 reach $100 \%$.
\end{abstract}

Keywords: improving, multiplication counting ability, strap

Abstrak: Penelitian ini bertujuan unutuk mendeskripsikan keaktifan siswa kelas ketika diterapkan media tali pas dan peningkatan hasil belajar siswa kelas V SDN Paciran I Lamongan tahun pelajaran 2016/2017 dalam menyelesaikan operasi hitung perkalian melalui penggunaan tali pas. Penelitian ini tergolong penelitian tindakan kelas. Data yang diperoleh berupa hasil tes formatif, lembar observasi kegiatan belajar mengajar. Hasil belajar tentang operasi hitung perkalian dengan menerapkan media tali pas dari siklus 1 ke siklus 2 mengalami, peningkatan yang sangat memuaskan. Pada siklus 1 mengalami peningkatan siswa yang memenuhi KKM yaitu $50 \%$, sedangkan pada siklus 2 mencapai $100 \%$.

Kata kunci: meningkatkan, kemampuan operasi hitung perkalian, tali pas

\section{PENDAHULUAN}

Tidak dapat dipungkiri lagi jika perkembangan pesat di bidang teknologi informasi dan komunikasi dewasa ini dilandasi oleh perkembangan matematika di bidang teori bilangan, aljabar, analisis, teori peluang dan matematika distrik. Untuk menguasai dan mencipta teknologi di masa depan diperlukan penguasaan matematika yang kuat sejak dini.

Kekuatan dasar matematika bisa dikatakan terletak pada keterampilan menjumlahkan,mengurangi,mengalikan dan membagi. Karena itulah pondasi ini perlu dibangun sekuat mungkin agar peserta didik mempunyai bekal yang kuat pula untuk mempelajari matematika pada tingkatan-tingkatan selanjutnya. Sebagai Pendidik di Sekolah Dasar, tugas utama kita adalah membekali peserta didik dengan kemampuan berpikir logis, analitis, sistematis, kritis dan kreatif, serta kemampuan bekerjasama. Kompetensi tersebut diperlukan agar peserta didik dapat memiliki kemampuan memperoleh, mengolah, dan memanfaatkan informasi untuk bertahan 
hidup pada keadaanyang selalu berubah, tidak pasti, dan kompetitif.

$$
\text { Berbagai upaya untuk }
$$

meningkatkan hasil belajar matematika bukanlah hal baru, untuk itu guru harus banyak memberikan kesempatan pada siswa sesuai dengan tingkat kemampuanya. Semakin banyak kesempatan belajar yang diberikan kepada siswa, semakin tinggi prestasi belajar siswa. Guru harus memberikan kesempatan praktik dan menemukan sendiri. Kaidah ini sebenarnya sama dengan kaidah cina yang mengatakan bahwa " saya dengar saya lupa, saya lihat saya ingat, dan saya lakukan saya paham " ( E. Dale, dalam Arnie, 2002 : 75 ). Oleh karena itu proses pembelajaran tidak boleh tidak harus mempergunakan alat peraga matematika.

Pembelajaran matematika memiliki karakteristik tersendiri, yaitu : diajarkan secara bertahap, mengikuti metode spiral, berpola pikir deduktif, dan menganut kebenaran konsistensi. Merujuk pengertian ini, maka pembelajaran matematika harus banyak melibatkan siswa, dan juga perlu adanya optimalisasi penggunaan indera siswa.

Karakteristik siswa SD ditinjau dari masa perkembangannya termasuk dalam masa pra operasional kongkrit, sehingga membutuhkan sarana dan media yang menjembatani pola pikir menuju arah yang lebih kongkrit. Masa perkembangan siswa SD dalam belajar membutuhkan suasana bermain yang menyenangkan dan menuntut siswa aktif di kegiatan.

Siswa merupakan manusia pribadi yang otonom dan bukan sekedar obyek. Oleh karena itu siswa dipandang sebagai pribadi yang memiliki dorongan dan kemampuan untuk memenuhi sesuatu dari sumber belajar ( alat peraga ) untuk meningkatkan keterlibatan secara langsung dan interaksi siswa sebagai sumber belajar. Dalam kesempatan ini guru harus diingatkan akan karakteristik
Humanis Vol. 12 No. 1

anak usia Sekolah Dasar. Secara umum, karakteristi anak SD dalam buku Perkembangan peserta didik ( Mulyani Sumantri, $2009: 6.3$ ) sebagai berikut :

- Mereka secara ilmiah memiliki rasa ingin tahu yang kuat dan tertarik akan dunia sekitar yang mengelilingi diri mereka sendiri.

- Mereka senang bermain dan suka bergembira ria.

- Mereka suka mengatur dirinya untuk menangani berbagai hal, mengekplorasi suatu situasi dan mencobakan usaha baru.

- Mereka biasanya bergetar perasaannya dan terdorong untuk berprestai sebagaimana mereka tidak suka mengalami ketidakpuasan dan menolak kegagalan - kegagalan.

Uraian di atas dapat disimpulkan bahwa bagi anak SD, penjelasan guru tentang materi pelajaran akan lebih dipahami jika anak melaksanakan sendiri. Dengan demikian guru hendaknya merancang model pembelajaran yang memungkinkan anak terlibat langsung dalam proses pembelajaran.

Untuk memberikan semangat baru dan rasa senang mempelajari matematika dibutuhkan alat peraga. Dengan semangat dan minat yang tumbuh dari diri siswa itu sendiri diharapkan dapat meningkatkan prestasi belajar siswa.

Pada umumnya siswa mengatakan bahwa pelajaran matematika merupakan pelajaran yang sulit dan susah dipahami. Guru sebagai penyampai materi pelajaran hanya sekedar menyampaikan bahan ajar yang sesuai dengan rancangan program pembelajaran. Untuk memberikan pelatihan ketrampilan memahami soal soal matematika guru memberikan tugas melalui LKS yang ada dan sosl soal dari guru. Guru kurang memberikan elaborasi yang mudah dipahami dan menyenangkan. Guru jarang dan kurang memanfaatkan alat peraga dan hanya menerangkan secara lisan. 
Pernyataan ini juga sesuai dengan kenyataan yang ada di SDN Paciran I kecamatan Paciran kelas V pada pelajaran matematika materi operasi perkalian dengan ditandai hasil ketuntasan belajar yang rendah. Terbukti ada 8 siswa dari 14 siswa memiliki hasil belajar di bawah KKM yang ditentukan guru yaitu 70. Dari 14 siswa tersebut terdapat 2 siswa yang mendapat nilai 100 , 1 siswa mendapat nilai 90, 2 siswa mendapat nilai 80, 1 siswa mendapat nilai 70,2 siswa mendapat nilai 60,3 siswa mendapat 50, 4 siswa mendapat 40 .

Berdasarkan hasil refleksi yang dilakukan, ketidaktuntasan tersebut disebabkan oleh faktor kelemahan guru. Guru dalam menyampaikan materi tidak menggunakan media yang dapat membuat anak tertarik dan memperhatikan pelajaran yang menyebabkan beberapa siswa kurang memperhatikan guru dengan berbicara sendiri dengan temannya / bemain pensil. Dalam menyampaikan materi guru hanya melakukan metode ceramah dan kurang memberi contoh soal latihan menyebabkan beberapa siswa ramai dengan bercanda / berbicara dengan temannya sehingga dalam mengerjakan soal melebihi waktu yang ditentukan. Kurangnya guru memberi kesempatan menjawab pada murid yang kurang mampu / pasif menyebabkan beberapa siswa yang pasif lebih suka mencontoh jawaban temannya daripada mengerjakan sendiri.

Dengan gejala seperti itu maka diperlukan sebuah strategi pembelajaran baru untuk lebih memberdayakan siswa. Kegiatan pembelajaran yang dipimpin guru harus memberikan kesempatan kepada siswa untuk terlibat aktif dalam menelaah materi pelajaran. Keberadaan guru dalam kelas berfungsi sebagai fasilitator dalam arti guru sebagai penyedia / pembimbing untuk mempermudah kegiatan pembelajaran.
Humanis Vol. 12 No. 1

Dengan begitu, materi pelajaran yang dipelajari siswa bukan sesuatu yang dicekokkan tetapi sesuatu yang dicari, dipahami, kemudian dilaksanakan dalam kehidupan sehari - hari. Guru harus menciptakan pendidikan yang bermakna di kelas yang aktif, asyik, dan senang serta hasilnya memuaskan, guru setidaknya dituntut mampu menghasilkan berbagai variasi pembelajaran dalam pengelolaan kelas.

Media pembelajaran merupakan suatu sarana yang dapat digunakan untuk memungkinkan terjadinya proses belajar pada diri siswa dan atau dapat digunakan untuk meningkatkan efektifitas kegiatan pembelajaran. Dalam pembelajaran, media memiliki banyak fungsi / kegunaan, antara lain :

- Mengatasi berbagai hambatan proses komunikasi, dan sikap pasif siswa dalam belajar.

- Menimbulkan kegairahan belajar.

- Menfokuskan / menarik perhatian.

- Memungkinkan mendekatkan interaksi langsung dengan lingkungan nyata.

- Memberikan perangsang yang sama untuk mempersamakan pengalaman dan menimbulkan persepsi yang sama.

Berdasarkan uraian diatas, untuk menciptakan pembelajaran yang aktif dan menyenangkan maka guru harus menggunakan media dalam pembelajaran dan memperbanyak latihan soal. Alasan itulah yang membuat penulis melakukan penelitian.

Adapun tujuan penelitian adalah :

1. Untuk mengetahui dan mendeskripsikan peningkatan hasil belajar siswa kelas V SDN Paciran I Lamongan tahun pelajaran 2016 / 2017 dalam menyelesaikan operasi hitung perkalian melalui penggunaan tali pas.

2. Untuk mendeskripsikan keaktifan siswa kelas V SDN Paciran I Paciran tahun pelajaran 2016 / 2017 ketika diterapkannya media tali pas 
dalam menyelesaikan operasi hitung perkalian .

\section{METODE PENELITIAN}

Penelitian ini merupakan Penelitian Tindakan Kelas ( Classroom Action Research), karena penelitian dilakukan untuk memecahkan masalah pembelajaran di kelas. sebanyak tiga putaran. Setiap putaran terdiri dari empat tahap yaitu: rancangan, kegiatan dan pengamatan, refleksi, dan refisi. Siswa yang dijadikan subyek pelaksanaan perbaikan adalah siswa kelas V SDN Paciran I Kecamatan Paciran dengan jumlah siswa 14 orang terdiri dari 4 siswa perempuan dan 10 siswa laki - laki. Data yang diperoleh berupa hasil tes formatif, lembar observasi kegiatan belajar mengajar.

\section{HASIL PENELITIAN DAN PEMBAHASAN \\ Siklus 1 \\ Perencanaan}

Perencanaan

penelitian

dilaksanakan di kelas tempat peneliti menajar bersama supervisor 2 yang merupakan pengawas peneliti. Pertama tama, peneliti mengidentifikasi masalah, menganalisis masalah, melakukan refleksi kemudian merencanakan solusi perbaikan. Adapun langkah - langkah yang dilakukan peneliti adalah :
Humanis Vol. 12 No. 1

- Menyiapkan materi yang tersusun jelas, sitematik dengan berbagai metode.

- Menyiapkan media tali pas, fasilitas dan sarana pendukukung yang diperluhkan serta buku - buku penunjang dan lembar kerja siswa.

- Menyiapkan lembar observasi / pengamatan aktV itas siswa dan guru dari awal sampai akhir pembelajaran.

- Menyiapkan daftar nilai.

- Menentukan target pencapaian hasil belajar sesuai dengan $\mathrm{KK}$ adalah $40 \%$.

- Menyiapkan waktu pelaksanaan perbaikan siklus 1, yaitu hari Kamis, tanggal 14 Oktober 2016.

\section{Pelaksanaan}

Pelaksanaan pembelajaran dilaksanakan pada hari Kamis. tanggal 14 Oktober 2016 jam ke 1 dan 2 selama 2 x 35 menit dengan fokus untuk memperbaiki tentang operasi hitung perkalian. Dalam pelaksanaan pembelajaran peneliti mengawali pembelajaran dengan melakukan absensi, apersepsi, dan menginformasikan tujuan pembelajaran. Pada kegiatan inti yang dilakukan guru adalah memberi penjelasan singkat tentang perkalian dengan media tali pas, mengadakan tanya jawab, memberikan soal dan memberikan kesimpulan.

Berikut merupakan hasil penilaian terhadap siswa selama siklus 1 :
Tabel 1 Nilai Hasil Belajar Siswa Tentang Operasi Hitung Perkalian Pada Siklus 1

\begin{tabular}{|c|l|c|c|}
\hline No. & \multicolumn{1}{|c|}{ Nama Siswa } & Prasiklus & Siklus I \\
\hline 1 & Abelia Septia Ayunda & 74 & 40 \\
\hline 2 & Fahmi Fanani & 40 & 40 \\
\hline 3 & Hikmal bayu Firmansyah & 50 & 60 \\
\hline 4 & Karyo Pamungkas K.N. & 60 & 40 \\
\hline 5 & Hanifatus Sholikhah & 40 & 60 \\
\hline 6 & Krisna Surya Febriansyah & 60 & 40 \\
\hline 7 & Kaila Aimatus Sholikhah & 40 & 60 \\
\hline
\end{tabular}




\begin{tabular}{|c|l|c|c|}
\hline 4 & Muh. Yudistira & 90 & 100 \\
\hline 9 & Muhamad Dimas Saputra & 40 & 40 \\
\hline 10 & Moch. Nur Ismail & 40 & 40 \\
\hline 11 & Rahmad Bayu Firmansyah & 40 & 60 \\
\hline 12 & Satrio Dwi Cahyono & 50 & 60 \\
\hline 13 & Yoda Argenta Pratama & 100 & 100 \\
\hline 14 & Mutiah Khoirunnsa & 50 & 40 \\
\hline & Rata-rata & 60,71 & 67,14 \\
\hline & KKM & 70 & 70 \\
\hline
\end{tabular}

\section{Pengamatan}

Supervisor 2 adalah pengamat terhadap guru dan siswa pada saat perbaikan pembelajaran di kelas. Berikut ini aspek yang diobservasi oleh supervisor 2 beserta hasil rekapitulasi observasi terhadap kegiatan siswa dalam pembelajaran siklus 1 .

Tabel 2 Rekapitulasi observasi terhadap kegiatan siswa siklus 1

\begin{tabular}{|c|l|c|c|c|}
\hline \multirow{2}{*}{ No } & \multicolumn{1}{|c|}{ Aspek yang di observasi } & \multicolumn{3}{c|}{ Hasil perkalian } \\
\cline { 3 - 5 } & & $\mathrm{B}$ & $\mathrm{C}$ & $\mathrm{K}$ \\
\hline 1 & Antusias dalam pembelajaran & $\sqrt{ }$ & & \\
\hline 2 & Menggunakan media & & $\sqrt{ }$ & \\
\hline 3 & Mengajukan pertanyaan & & $\sqrt{ }$ & \\
\hline 4 & Menjawab pertanyaan guru & & $\sqrt{ }$ & \\
\hline 5 & Mengajukan pendapat & & & $\sqrt{ }$ \\
\hline 6 & Mengerjakan tugas & & $\sqrt{ }$ & \\
\hline 7 & Perhatian dalam pembelajaran & $\sqrt{ }$ & & \\
\hline 8 & Kemampuan kerjasama & & $\sqrt{ }$ & \\
\hline
\end{tabular}

Hasil observasi terhadap kegiatan siswa pada siklus 1 menunjukan bahwa antusias, perhatian dan keaktifan siswa dalam menggunakan media tali pas sudah baik. Sedangkan aspek yang perlu ditingkatkan lagi adalah keberanian bertanya, menjawab dan kerjasama dengan teman.

Berikut ini aspek yang diamati oleh supervisor 2 beserta hasil rekapitulasi observasi terhadap guru / peneliti dalam perbaikan pembelajaran siklus 1

\section{Tabel 3 Rekapitulasi Hasil Observasi Terhadap Kegiatan Guru Siklus 1}

\begin{tabular}{|c|l|c|c|c|}
\hline \multirow{2}{*}{ No } & \multicolumn{1}{|c|}{ Aspek yang diamati } & \multicolumn{3}{|c|}{ Hasil Penilaian } \\
\cline { 3 - 5 } & \multicolumn{1}{|c|}{$\begin{array}{c}\text { B } \\
\text { pemggunaan strategi, teknik, metode }\end{array}$} & & $\sqrt{ }$ & \\
\hline 2 & Penggunaan media kelas & $\sqrt{ }$ & & \\
\hline 3 & Penyampaian materi pelajaran & $\sqrt{ }$ & & \\
\hline 4 & Memandu diskusi siswa & & $\sqrt{ }$ & \\
\hline 5 & Kualitas soal yang diberikan & $\sqrt{ }$ & & \\
\hline 6 & MemotV asi siswa & $\sqrt{ }$ & & \\
\hline 7 & Pengelolaan kelas & & $\sqrt{ }$ & \\
\hline
\end{tabular}

Hasil observasi pada siklus 1 menunjukan bahwa guru dalam hal menggunakan media, menyampaikan materi pelajaran, memberikan soal dan memotV asi siswa sudah baik.sedangkan hal - hal yang perlu ditingkatkan lagi 
adalah penggunaan strategi, teknik, metode, memandu diskusi siswa dan pengelolaan kelas.

\section{Refleksi}

1. Keberhasilan pelaksanaan siklus 1 adalah :

- Penurunan jumlah siswa yang mendapat nilai di bawah KKM.

- Peningkatan rata - rata kelas.

- Minat dan antusias serta kemampuan siswa meningkat,

- Siswa dapat aktif dalam kegiatan pembelajaran.

2. Kelemahan pelaksanaan siklus 1adalah:

- Keberaniaan siswa dalam bertanya, menjawab dan berpendapat masih kurang

- Penggunaan media belum optimal.

- Kurangnya ketrampilan guru dalam mengelola dan memandu diskusi kelas.

\section{Siklus 2}

\section{Perencanaan}

Dari hasil yang dicapai pada siklus 1, peneliti bersama supervisor 2 melaksanakan perbaikan pembelajaran siklus 2 yang kegiatan pada siklus 2 ini terfokus untuk memperbaiki kekurangan - kekurangan pada siklus 1. Adapun langkah - langkah perencanaannya adalah :

- Membuat rencana perbaikan pembelajaran ( RPP )

- Menyiapkan materi yang tersusun jelas, sitematik dengan berbagai metode.

- Menyiapkan media tali pas, fasilitas dan sarana pendukukung yang diperluhkan serta buku - buku penunjang dan lembar kerja siswa.

- Membagi siswa menjadi 3 kelompok, masing - masing terdiri dari $4-5$ orang.

- Menyiapkan lembar observasi / pengamatan aktV itas siswa dan guru dari awal sampai akhir pembelajaran.

- Menyiapkan daftar nilai.

- Menentukan target pencapaian hasil belajar sesuai dengan KK adalah 100 $\%$

- Menentukan waktu pelaksanaan perbaikan siklus 2, yaitu pada hari Kamis, tanggal 25 Oktober 2016.

\section{Pelaksanaan}

Pelaksanaan

pembelajaran dilaksanakan pada hari Kamis, tanggal 25 Oktober 2016 jam ke 1 dan 2 selama 2 x 35 menit dengan fokus untuk memperbaiki tentang operasi hitung perkalian. Dalam pelaksanaan pembelajaran peneliti mengawali pembelajaran dengan melakukan salam, absensi, apersepsi, dan menginformasikan tujuan pembelajaran. Pada kegiatan inti yang dilakukan guru tanya jawab tentang perkalian, membagi siswa menjadi 3 kelompok yang anggotanya $4-5$ anak, memberi penjelasan singkat tentang perkalian dengan media tali pas dan cara menggunakannya, memberikan tugas dengan mencatat hasil perkalian tali yang diberikan sebanyak jumlah anggota secara bergantian, menilai tugas siswa dan memberikan kesimpulan.

Berikut merupakan hasil penilaian terhadap siswa selama siklus 2 :

Tabel 4 Nilai Hasil Belajar Siswa Tentang Operasi Hitung Perkalian Pada Siklus 2

\begin{tabular}{|l|l|l|l|}
\hline No & Nama siswa & Pra siklus & Siklus 1 \\
\hline
\end{tabular}




\begin{tabular}{|l||l|c|c|}
\hline 1 & Abelia Septia Ayunda & 40 & 40 \\
\hline 2 & Fahmi Fanani & 40 & 70 \\
\hline 3 & Hikmal bayu Firmansyah & 60 & 40 \\
\hline 4 & Karyo Pamungkas K.N. & 60 & 40 \\
\hline 5 & Hanifatus Sholikhah & 40 & 100 \\
\hline 6 & Krisna Surya Febriansyah & 40 & 90 \\
\hline 7 & Kaila Aimatus Sholikhah & 60 & 40 \\
\hline 4 & Muh. Yudistira & 100 & 100 \\
\hline 9 & Muhamad Dimas Saputra & 40 & 40 \\
\hline 10 & Moch. Nur Ismail & 40 & 90 \\
\hline 11 & Rahmad Bayu Firmansyah & 60 & 40 \\
\hline 12 & Satrio Dwi Cahyono & 60 & 40 \\
\hline 13 & Yoda Argenta Pratama & 100 & 100 \\
\hline 14 & Mutiah Khoirunnsa & 40 & 40 \\
\hline \hline & Rata - rata & 70 & 45 \\
\hline & KKM & & 70 \\
\hline \hline
\end{tabular}

\section{Pengamatan}

Berikut ini aspek yang diobservasi oleh supervisor 2 beserta hasil rekapitulasi observasi terhadap kegiatan siswa dalam pembelajaran siklus 1 .

Tabel 5 Rekapitulasi observasi terhadap kegiatan siswa siklus 2

\begin{tabular}{|c|l|c|c|c|}
\hline \multirow{2}{*}{ No } & \multicolumn{2}{|c|}{ Aspek yang di observasi } & \multicolumn{3}{|c|}{ Hasil perkalian } \\
\cline { 3 - 5 } & & B & C & K \\
\hline 1 & Antusias dalam pembelajaran & $\sqrt{ }$ & & \\
\hline 2 & Menggunakan media & $\sqrt{ }$ & & \\
\hline 3 & Mengajukan pertanyaan & $\sqrt{ }$ & & \\
\hline 4 & Menjawab pertanyaan guru & $\sqrt{ }$ & & \\
\hline 5 & Mengajukan pendapat & $\sqrt{ }$ & & \\
\hline 6 & Mengerjakan tugas & $\sqrt{ }$ & & \\
\hline 7 & Perhatian dalam pembelajaran & $\sqrt{ }$ & & \\
\hline 4 & Kemampuan kerjasama & $\sqrt{ }$ & & \\
\hline
\end{tabular}

Dari hasil pengamatan tabel di atas menunjukan bahwa perbaikan pada pembelajaran siklus 2 oleh peneliti dinilai oleh supervisor 2 hasilnya baik.
Berikut ini aspek yang diamati oleh supervisor 2 beserta hasil rekapitulasi observasi terhadap guru / peneliti dalam perbaikan pembelajaran siklus 2

Tabel 6 Rekapitulasi Hasil Observasi Terhadap Kegiatan Guru Siklus 2

\begin{tabular}{|c|l|c|c|c|}
\hline \multirow{2}{*}{ No } & \multicolumn{1}{|c|}{ Aspek yang diamati } & \multicolumn{3}{|c|}{ Hasil Penilaian } \\
\cline { 3 - 5 } & \multicolumn{1}{|c|}{ B } & C & $\mathrm{K}$ \\
\hline 1 & $\begin{array}{l}\text { Penggunaan strategi, teknik, metode } \\
\text { pembelajaran }\end{array}$ & $\sqrt{ }$ & & \\
\hline 2 & Penggunaan media kelas & $\sqrt{ }$ & & \\
\hline 3 & Penyampaian materi pelajaran & $\sqrt{ }$ & & \\
\hline 4 & Memandu diskusi siswa & $\sqrt{ }$ & & \\
\hline 5 & Kualitas soal yang diberikan & $\sqrt{ }$ & & \\
\hline 6 & MemotV asi siswa & $\sqrt{ }$ & & \\
\hline 7 & Pengelolaan kelas & $\sqrt{ }$ & & \\
\hline
\end{tabular}


Dari tabel di atas dapat diketahui bahwa dalam pelaksanan perbaikan pembelajaran pada siklus 2 ini semua aspek mengalami peingkatan.

\section{Refleksi}

Selesai melaksanakan perbaikan pembelajaran, bersama supervisor 2 peneliti mengadakan refleksi setelah mengetahui hasil tes belajar siswa. Adapun hasil dari refleksi siklus 2 adalah:

1. Nilai rata - rata hasil belajar siswa pada siklus 2 meningkat menjadi 45 , sebelumnya pada siklus 1 hanya 67 , 14.

2. Siswa berhasil memenuhi target yang ditentukan, yaitu memenuhi KKM (70).

3. Kemampuan dan keaktV itasan siswa mengalami peningkatan.

4. Pembelajaran dapat menambah $\operatorname{mot} \mathrm{V}$ asi bagi siswa.

\section{SIMPULAN}

Dari semua hasil perbaikan pembelajaran siswa kelas V semester 1 SDN Paciran I , kecamatan Paciran baik pada pra perbaikan,perbaikan siklus 1 dan siklus 2 dapat disimpulkan sebagai berikut :

1. Kemampuan siswa terhadap materi pelajaran operasi hitung perkalian sebelum menggunakan media tali pas sangat lemah.

2. Keaktifan siswa dalam pembelajaran dengan menggunakan media tali pas meningkat karena menyenangkan dan tidak membosankan.

3. Keaktifan guru sebagai peneliti juga mengalami peningkatan dalam proses belajar mengajar dengan menggunakan media tali pas.

4. Hasil belajar tentang operasi hitung perkalian dengan menerapkan media tali pas dari siklus 1 ke siklus 2 mengalami peningkatan yang sangat memuaskan. Pada siklus 1 mengalami peningkatan siswa yang memenuhi KKM yaitu $50 \%$, sedangkan pada siklus 2 mencapai $100 \%$.

\section{DAFTAR PUSTAKA}

Azhar Arsyad, 1996, Media Pembelajaran. Jakarta : PT Raja Grafindo Persada

E.T. Rusefendi, 1942. Pengajaran Matematika Modern. Bandung : Tarsito

Herman Maiser, 1945. Kompedium Diktaktik Matematika. Bandung : Remadja Karya

Muchtar A. Karim dkk, 1996.Pendidikan Matematika I. Malang : IKIP Malang

Nasution, 1942. Berbagai Pendekatan Dalam Proses Belajar Mengajar. Bandung : Sinar Baru AC Grafindo

Tim Pengembang Kurikulum, 2004.Kurikulum 2004. Jakarta : Departemen Pendidikan Nasioanal

BNSP, 2006. Standar Isi untuk Satuan Pendidikan Dasar dan Menegah. Jakarta : Departemen Pendidikan Nasional

Nana Sudjana, 1947. Dasar - Dasar Proses Belajar - Mengajar. Bandung : Sinar Baru AC Grafindo

Nana Sudjana, 1997. Filsafat Pendidikan. Bandung : Sinar Baru AC Grafindo

Suharsimi Arikunto, 1997. Prosedur Penelitian. Jakarta : Reneka Cipta

Tim Matematika, 2004. Cerdas Matematika 4 SD. Jakarta : Yudistira 